\title{
A história de luta nos movimentos sindicais: práticas informacionais
}

The history of struggle in the trade union movements: informational practices

\section{Adriana Soares Viana ${ }^{1}$ \\ Rubens Alves da Silva ${ }^{2}$}

Resumo: Relata a investigação do sindicato como espaço de interlocução. Visa compreender as ações e práticas informacionais dos sujeitos a partir de seu contexto, histórico, político, econômico e sociocultural. Traz um breve histórico do movimento sindical no Brasil. Por fim, apresenta os resultados de um estudo de caso da investigação realizada em um sindicato de servidores públicos federais lotados em uma universidade federal.

Palavras-chave: Práticas informacionais. Sindicato. Sindicalismo. Movimentos sociais.

Abstract: Reports the investigation of the union as a space for dialogue. It aims to understand the informational actions and practices of the subjects from their context, historical, political, economic and socio-

1 Possui Mestrado em Ciência da Informação pela Escola de Ciência da Informação da Universidade Federal de Minas Gerais (2015), Especialização em Gestão de Instituições Federais de Educação Superior (GIFES) pela Faculdade de Educação FAE/UFMG (2013), Especialização em Biblioteconomia pela FIJ-RJ (2011) e Graduação em Biblioteconomia pela Escola de Ciência da Informação da Universidade Federal de Minas Gerais (2007). Atua como Bibliotecária-documentalista na Faculdade de Direito da Universidade Federal de Minas Gerais.

2 Possui Mestrado em Direito pela Faculdade de Direito do Sul de Minas, Brasil(2013). Professor adjunto de Direito. do Centro Universitário Luterano de Manaus, Brasil 
cultural. It brings a brief history of the trade union movement in Brazil. It presents the results of a case study of research conducted in a union of federal civil servants housed at a federal university.

Keywords: Informational practices. Syndicate. Unionism. Social movements.

\section{INTRODUÇÃO}

A origem dos sindicatos se deu a partir da necessidade da criação de instituições que pudessem defender os interesses de ordem econômica e social dos trabalhadores perante os empregadores. A história sindical brasileira é atípica se comparada com as demais. Isso se deve aos movimentos políticos instaurados no país, no decorrer da sua história.

O sindicato é um movimento social no qual os trabalhadores lutam por melhorias salariais e por melhores condições de trabalho. Antunes (1985, p. 13) ao falar dos sindicatos, destaca que se trata de associações criadas pelos operários para sua própria segurança, através da defesa de direitos importantes como: a manutenção de um salário digno e uma jornada de trabalho menos extenuante. Dessa forma, a luta dos sindicatos baseia-se nas lutas cotidianas da classe trabalhadora.

A informação desempenha papel fundamental nos sindicatos, pois o movimento social ocorre a partir da interação dos atores sociais na busca por informação e conhecimento. Para Pinto (2004) essa busca permite aos atores construírem suas próprias histórias, tornando-se capazes de lutar para conquistar seu espaço como indivíduos iguais na sociedade. É importante ressaltar que a informação não garante a transformação, apenas oferece ao indivíduo a possibilidade de utilizá-la ou não em busca da construção do conhecimento e veio político nos indivíduos que anteriormente não tenham tido contato com um movimento de cunho social ou político.

Notadamente, os movimentos sindicais abrigam em seu bojo diversas formas discursivas que trazem consigo a proposta de trans- 
formações sociais. A informação sindical busca sensibilizar e estabelecer um diálogo com quem é representado pelo sindicato, busca ainda promover o fortalecimento da entidade junto à sociedade. Os sindicatos caracterizam-se como espaços que abrigam grande fluxo informacional, uma vez que a informação que circula nesse ambiente é um elemento chave. A comunicação entre as partes envolvidas ocorre através de diversas fontes de informação ou meios: Folhetos, jornais, boletins, site, assembléias, Grupos de trabalho (GT), entre outros. Esse grande fluxo informacional é responsável por auxiliar tanto os dirigentes quanto a base sindical, composta pelos trabalhadores.

A seguir relataremos um estudo de caso realizado em um sindicado de servidores públicos federais de uma universidade federal. A escoIha metodológica feita para o desenvolvimento do trabalho investigativo de campo apoia-se no método qualitativo. A pesquisa atentou para o fato dos sujeitos interlocutores serem diferentes quanto ao hábito e ao tipo de comportamentos adotado no processo de busca de informações e uso dos espaços.

\section{A HISTÓRIA RECENTE DO SINDICALISMO BRASILEIRO E O MUNDO DO TRABALHO}

A consolidação das leis trabalhistas (CLT) data de $1^{\circ}$ de maio de 1943. A CLT, estabeleceu uma série de diretrizes a serem seguidas pelos sindicatos brasileiros, dentre as quais destacam-se o direito do Estado efetuar intervenções nos sindicatos, bem como o dever dos sindicatos contribuírem com o Estado, e ainda a prestação de contas anual obrigatória ao Ministério do Trabalho (PINTO, 2004).

Nesse artigo, optamos por delimitar o aspecto histórico do movimento sindical a partir dos anos 1940, período do governo Getúlio Vargas.

No período político que se estabeleceu entre os anos 1943 e 1964, conhecido como democrático, ocorreu a manutenção do modelo corporativista, que restringia a autonomia sindical. Segundo Farias (2003), no modelo corporativista o Estado passou a "sujeitar" os sindicatos, 
retirando a sua autonomia, trazendo a regra de monossindicalismo, dando como opção aos trabalhadores o sindicato único.

Nem mesmo com a criação da Constituição de 1946 houve mudanças significativas, pelo contrário, conforme Pinto $(2004$, p.78) a mesma "limitou as condições legais de paralisação do trabalho e proibiu greves nos setores de serviços considerados fundamentais".

O sindicalismo da década de 60 , por sua vez, foi considerado por alguns estudiosos como inexpressivo, mas parte desse pensamento se deu devido à política militarista imposta no Brasil nesse período, que instaurou uma política ditatorial que acabou, em parte, com os direitos e liberdade dos cidadãos. Nesse período o movimento de greve era visto como um "atentado à segurança nacional". O governo militar através de medidas legais delegava apenas o papel de assistencialismo aos sindicatos, que passaram a serem liderados por representantes nomeados pelo próprio governo militar. Pinto (2004, p.79) ressalta que com o golpe militar de 1964 foi imposto "um sindicalismo de intervenção, com clara tendência à acumulação de capital. Os governos que se seguiram passaram a promover uma política de arrocho salarial pela fixação de reajustes mínimos". Boito Jr. (1991, p. 47) dá uma visão geral do que foi a atuação sindical durante o período da ditadura militar:

A principal - e praticamente única - atividade dos milhares de sindicatos oficiais no período 1968-1978 consistiu em implantar ou expandir grandes e dispendiosos serviços assistenciais - serviços médico, odontológico, laboratoriais, jurídico, colônia de férias, bolsas de estudos, cooperativas de consumo, etc. convertendo-se, esses sindicatos, em espécies de agências da Previdência Social. (BOITO JR. 1991, p. 47).

Já na década de 70, apesar da opressão por parte do governo militar, muitos trabalhadores resistiram no propósito de fortalecer o movimento sindical. Nesse período foi percebido que o sistema corporativista vigente permitia certa autonomia e que esta variava de acordo com o tipo de governo. Conforme Pinto $(2004$, p80) optava-se "pela colocação de lideranças coniventes com o regime". A autora ainda destaca: 
Esse tipo de tutela do Estado, aliada à repressão e à falta de atendimento às demandas por melhores condições de trabalho, acabou por gerar uma insatisfação entre os mais politizados, no contexto do movimento sindical. Fato que resultou no questionamento de toda a estrutura sindical vigente. Esse movimento ficou conhecido como o movimento do "Novo Sindicalismo" (PINTO, 2004, p. 80).

O Novo Sindicalismo ficou marcado pelos movimentos de greves dos metalúrgicos, que teve início em maio de 1978, no $A B C$ paulista. As greves dos metalúrgicos nesse período é vista como um marco para o desenvolvimento do novo sindicalismo no Brasil. O novo movimento sindical buscava "a autonomia e a liberdade sindical", sobretudo a defesa do direito de livre manifestação, a organização dos trabalhadores em prol dos seus direitos, e a luta contra a exploração do trabalho.

Para Mattos (1998) apud Pinto (2004, p.81) "o novo sindicalismo surgiu de um movimento de massas, organizado a partir dos trabalhadores, sem iniciativa da cúpula dos dirigentes sindicais". Para Pinto os protestos tomaram força a partir do questionamento do papel do Estado nos sindicatos, "da burocratização" e do atrelamento político do Estado, da prioridade dada ao assistencialismo, do carreirismo dos dirigentes e da política conciliatória dos interesses de classes". A burocratização dos sindicatos é a forma como ficou conhecida a ação dos dirigentes sindicais e dirigentes de diversas organizações de trabalhadores de aplicar uma política que fez com que esses espaços deixassem de cumprir o papel de defender os trabalhadores, tornando-se organizações de cooperação com os patrões. Essa política começa a ser desenvolvida a partir do momento em que os sindicatos vão crescendo, adquirindo recursos materiais que dão aos dirigentes vantagens pessoais que os fizeram afastar dos trabalhadores.

Nesse contexto, a democracia passa a ocupar papel de destaque na dinâmica política do Brasil. Alguns autores destacam que o novo sindicalismo contribuiu em 1980 para a criação do Partido dos TrabaIhadores (PT); da Central Única dos Trabalhadores (CUT), em 1983, e da movimentação em prol das eleições diretas para presidente, em 
1984 (BOITO JR., 1991; FRANÇA, 2001 apud Adão, 2008) Com a democracia em evidência no país, devido às mudanças políticas ocorridas e com o apoio da sociedade, é importante ressaltar que os movimentos sindicais tiveram importância e expressividade no movimento das Diretas Já. Dessa forma, o novo sindicalismo contribuiu para a aniquilação do movimento ditatorial no Brasil.

De fato, desde o começo da década de 80, o sindicalismo brasileiro ganhou destaque internacional, sendo conhecido como um dos mais combativos. Nessa época os sindicatos eram reconhecidos por conquistar melhorias para as categorias dos trabalhadores. Houve um fortalecimento dos movimentos sindicais brasileiros.

Com o movimento sindicalista bastante ativo no decorrer dos anos 80, a Constituição de 1988, garante o direito de greve aos trabalhadores, desde que haja a aprovação do sindicato e dos trabalhadores, devendo haver votação quanto ao início e ao fim da greve.

Pochmann (2005) destaca que o movimento de greve transformou-se num dos principais instrumentos de "valorização e vocalização dos interesses coletivos dos trabalhadores, apontando o elevado grau de insatisfação, sobretudo com a realidade socioeconômica e com o caráter autoritário e antidemocrático", que a seu ver ainda permanecia no interior das relações de trabalho. Essa conquista é considerada como muito importante mesmo nos dias de hoje, pelos trabalhadores, na busca de seus direitos, sendo que o movimento de greve é um importante instrumento de combate.

Nos anos 90 o movimento sindicalista brasileiro tomou novos rumos devido à reestruturação produtiva e à economia neoliberal. $\mathrm{Na}$ economia neoliberal é defendida a absoluta liberdade de mercado e uma restrição à intervenção estatal sobre a economia, só devendo esta ocorrer em setores imprescindíveis e ainda assim em um grau mínimo. A reestruturação produtiva consistiu nas transformações que ocorreram nos processos produtivos em todo o mundo, em especial a partir da década de 1960, com a introdução do modelo toyotista na organização do trabalho. Podem ser destacadas alterações tanto na oferta quanto na demanda de trabalho. 
A partir da instabilidade e incertezas do mercado de trabalho, os sindicatos passaram a agir na defensiva. Nesse contexto houve o crescimento do mercado informal, em detrimento da criação de vagas de emprego. Para Pochmann (2005, p.172), o sindicalismo brasileiro, a partir da década de 90 , perdeu força e passou a enfrentar diversas dificuldades, que com as mudanças ocorridas na economia mundial, ficaram em evidência:

A atual estratificação social no interior da estrutura ocupacional esvaziou opapeldossindicatos, contendo-os nadefesarestritados interesses de parceladosempregosassalariadosformais. Assim, 0 corporativismo cresce, ao mesmo tempo que amplia-se a quantidade de ocupações sem organização de representação de interesses. (...) Onde foram mais predominantes, as políticas neoliberais tornaram mais explícita a situação de fragilidade sindical, com a perda de associados, a redução da cobertura dos contratos coletivos de trabalho, o esvaziamento das greves e a elevação do desemprego diante do baixo crescimento econômico. (...) A forte queda no movimento paredista ocorreu paralelamente à presença de governos comprometidos com políticas anti-labor, responsáveis pela condução da economia sem maiores compromissos com a produção e o emprego nacionais. (POCHMANN, 2005, p. 172).

A partir dos anos 90 o movimento sindical passa a viver uma situação difícil, devido às políticas neoliberais disseminadas mundialmente. Houve uma forte queda na adesão ao movimento, o governo brasileiro passa a não priorizar os compromissos com a produção e empregos nacionais (POCHMANN, 2005). Nesse período o movimento sindical passa a sofrer pressões por parte do governo. É destacado o emprego do poder coercitivo do Estado frente aos movimentos sindicais durante $o$ governo do presidente Fernando Henrique Cardoso.

Emblemático neste sentido foi a repressão à greve dos petroleiros, em 1995, quando o governo federal demite de seus postos de trabalho aqueles que eram dirigentes sindicais e ordena a entrada de canhões dos tanques do Exército, que foram apontados contra os trabalhadores nas refinarias. 
Especialmente no setor público, atuando contra o sindicalismo há uma propaganda do mesmo como uma "ideologia derrotada", uma vez que a partir da década de 90 os governantes passaram a disseminar a imagem negativa do servidor público, que muitas vezes foi caracterizado como "marajá" ou "parasita". Essa imagem criada enfraquecera o movimento grevista no setor público, pois esse setor mais do que qualquer outro necessita do apoio da opinião pública (VENTURINI, 2006). Por outro lado, para Noronha apud Venturini (2006) nesse período acaba havendo um desenvolvimento expressivo do sindicalismo no setor público, já que o risco de desemprego nesse campo é menor que nos demais.

Em suas colocações, Sandri (1995, p.72) citado por Oliveira (2005, p.49) destaca um ponto importante no papel do sindicalismo brasileiro, que apesar do pressuposto dos sindicatos terem sido criados para defender os interesses de ordem econômica e social dos trabalhadores perante os empregadores, "o tradicional modelo sindical nunca passou de um representante dos trabalhadores para objetivo de negociação e, portanto, de uma instituição amenizadora dos conflitos de classes".

O mesmo autor ainda destaca que o modelo tradicional de sindicalismo se torna ainda mais marginalizado na sociedade entrando em profunda crise quando o capitalismo surge como única alternativa para o mercado de trabalho, a partir do que observa-se como tendência mundial (OLIVEIRA, 2005).

Cabe relevar que historicamente, no mercado capitalista, o trabalhador é visto simplesmente como instrumento necessário à obtenção de lucro. Nesse caso, não se trata da produção para o simples usufruto das necessidades básicas humanas, mas para a superexploração da mais-valia como condição prioritária dos meios de produção capitalistas. O conceito de mais valia pode ser compreendido como um excedente quantitativo de trabalho, ou seja, no capitalismo, o trabalhador não recebe o valor real do seu trabalho, apenas o necessário para sobreviver, pois os donos dos meios de produção visam ao lucro. A mais valia é, dessa forma, a base da acumulação capitalista (MARX, 1944). 
Para Menezes (2008) "com o advento do capitalismo, que subordina o trabalho às premissas do capital, o modo de produção das mercadorias em série somente poderia existir com a exploração do trabalhador na esteira das fábricas e na alienação coletiva em detrimento do saber cognitivo". Torna-se claro o poder que o sistema capitalista exerce sobre o indivíduo, sobretudo através da tecnologia, como instrumento massificador. Mas cabe ressaltar também que este instrumento é culturalmente necessário ao desenvolvimento do indivíduo e do próprio sistema. Atualmente a precarização e consequente informalização do trabalho é responsável por renovar a configuração das relações de classe e dos movimentos sociais. Em especial, no serviço público, que destacava-se pelos movimentos com grande adesão da sua base, o atual governo trabalha para a desconstrução do movimento sindical, criminalizando os atos realizados no âmbito das universidades e institutos públicos federais. Os desafios colocados por essas transformações revelam a necessidade de adaptação dos sindicatos das diferentes classes trabalhadoras, independente das suas particularidades.

\section{PRÁTICAS INFORMACIONAIS NOS SINDICATOS}

Alguns autores avaliam que no cotidiano dos sindicatos, entidades representativas, a informação possui também um valor estratégico, contribuindo em variadas atividades desenvolvidas como: na realização de pesquisas, debates, trabalhos, pareceres, entre outros. Para o dirigente sindical a informação é parte fundamental da ação sindical (ARAÚJO, 1998, BAPTISTA, 2001, OLIVEIRA, 2005. ADÃO 2008).

O presente estudo investigou como as práticas informacionais são processadas no sindicato como espaço de interlocução. Considerou os indivíduos em seu contexto de ação, ou seja, nas suas interações e na construção e significação do seu mundo social (SILVA, 2008). Pinto e Araújo (2012) destacam a necessidade de se aprimorar o estudo da subjetividade dos usuários da informação, considerando as complexas relações que os cercam, com o objetivo de melhorar os serviços de 
informação, de forma que, para cada indivíduo, exista um serviço que atenda às suas necessidades.

Como práticas informacionais considera-se aqui o estudo dos fenômenos informacionais a partir da atuação e da perspectiva dos atores sociais (base e dirigentes do sindicato) na produção, organização, recebimento, disseminação e interpretação das informações no contexto sindical.

A disseminação e intercâmbio de informações os indivíduos tomam consciência dos seus direitos e deveres. Assim, ao estabelecerem "circuitos comunicacionais" os sujeitos constroem as práticas informacionais, que podem ser definidas como "ações de recepção, geração e transferência de informação que se desenvolvem através de circuitos comunicacionais que ocorrem nas formações sociais" (ARAÚJO, 2001, p.32). O estudo dessas práticas considera os significados atribuídos pelos indivíduos durante as ações de busca, uso e disseminação de informações (PINTO; ARAÚJO, 2012, p.223).

Para apreender os "hábitos informacionais", a escolha metodológica feita para o desenvolvimento do trabalho investigativo de campo apoiou-se no método qualitativo. O estudo de caso teve como campo um sindicato de servidores públicos federais de uma universidade federal. Atentou para o fato dos sujeitos interlocutores serem diferentes quanto ao hábito e ao tipo de comportamentos adotado no processo de busca de informações e uso desses espaços. Conforme a explicação de Baptista e Cunha (2007) a abordagem qualitativa permite o enfoque nos aspectos subjetivos da experiência e do comportamento humano, em suma, sendo inúmeras suas vantagens para a compreensão do processo.

\section{RESULTADOS}

Na pesquisa de campo, aplicamos entrevistas semiestruturadas que foram direcionadas aos dirigentes e a base sindical. Após um breve referencial teórico, enfatizamos as práticas informacionais desses indivíduos, com o propósito de compreender a dinâmica 
política desse contexto social e a sua influência para o desenvolvimento do movimento sindical.

Para a pesquisa de campo, a amostra foi constituída por oito interlocutores, representantes da população alvo para a realização da pesquisa.

Em relação aos resultados das entrevistas, os usuários das informações sindicais, ou seja, os trabalhadores identificam no sindicato uma entidade representante da categoria. A maior parte dos entrevistados relatou conhecer o sindicato da categoria como atuante, principalmente através dos movimentos de greves ou das assembleias organizadas com maior frequência nesse período, onde ocorre maior contato entre a base sindical e os dirigentes.

Os eventos de militância, as assembleias feitas durante os períodos de greve e mesmo, as reuniões realizadas periodicamente são caracterizados como espaços de discussões e de intercâmbio de informações úteis aos servidores. Esses encontros são também responsáveis pela democratização da informação.

A maioria dos entrevistados também afirmou que já se beneficiou com cursos oferecidos pela entidade. Cursos que tem como foco aumentar o nível de escolaridade dos servidores ou mesmo cursos de capacitação que visam a melhoria dos serviços prestados.

Dentre os serviços procurados, o mais indicado pelos entrevistados foi o serviço de assessoria jurídica. Muitos interlocutores identificaram nesse serviço de assessoria jurídica a principal relevância do sindicato para os trabalhadores que acompanham o movimento sindical. Esse serviço também é indicado como o mais procurado e acessível.

Alguns entrevistados indicaram o Centro de Memória como um serviço de cunho informacional, importante para o movimento. O centro de memória abriga uma biblioteca, com um pequeno acervo. E ainda um arquivo organizado por um profissional, que abriga toda a documentação relativa à história do sindicato.

Os GTs (Grupos de Trabalho) também foram indicados por alguns entrevistados como um importante serviço ofertado pelo sindicato, já que ele se configura como um espaço de discussão. Porém durante 
as entrevistas, constatamos que alguns dos GTs atualmente não estão funcionando na prática, apesar de já terem funcionado durante um período e possuir regulamentação, sofreram com a redução de verba. Devido à esse processo, atualmente, o sindicato tem feito programas de divulgação para adesão dos servidores não filiados.

Esses diferentes aspectos evidenciam como o sindicato é um espaço plural responsável por abrigar distintos serviços e práticas informacionais. Apesar desses departamentos prestarem serviços à base sindical, eles disponibilizam diferentes tipos de informação, em diversas instâncias que possibilitam distintas interpretações.

\section{CONSIDERAÇÕES FINAIS}

Apesar das dificuldades encontradas pelos sindicatos brasileiros, na luta pelos direitos dos trabalhadores, fica claro que para o fortalecimento de classe é essencial que haja um diálogo entre os sindicatos dos trabalhadores, Estado e empregadores, na busca da promoção dos direitos trabalhistas; solução dos problemas e desafios no mundo do trabalho; resolução dos conflitos e melhoria da produtividade, segurança e saúde ocupacional. O Estado representa um papel crucial no que diz respeito à relação entre capital e trabalho.

O Estado estabelece regras que ordenam a ligação entre trabalhadores e empresários, com função de regulamentar o trabalho e administrar os conflitos existentes do encontro destas duas forças, adotando (ou devendo adotar) uma postura de intervenção profunda nas relações entre empresários e trabalhadores tanto por meio da legislação, quanto por meio do Poder Judiciário (MATOS, 2012). Ainda que para outros autores o Estado não possa "ser visto como mero solucionador de problemas, já que o mercado não é, por si só, a fonte deles, atribuída à lógica capitalista de produção", como analisa Mollo (2001, p. 348).

Torna-se claro que os sindicatos brasileiros são de extrema importância para as diversas necessidades dos trabalhadores. Eles contribuem definitivamente para a formação cidadã uma vez que têm o papel de representar os trabalhadores; humanizando as relações de 
trabalho, ampliando direitos e evitando as perdas dos direitos já consolidados, contribuindo assim, para a mudança de muitas realidades.

A pesquisa objetivou conhecer as práticas informacionais dos servidores federais sindicalizados, a partir da dinâmica existente nesse contexto social. O tema não foi esgotado, dadas as particularidades de todos os tipos de sindicatos ou tipos de trabalhadores existentes. Mas, através do recorte proposto nas entrevistas foi possível estabelecer um diálogo rico em informações da realidade vivenciada no cotidiano desses servidores. Observou-se com a entrevista aplicada que foi possível apreender informações relevantes para desdobramentos do presente estudo.

O trabalho de campo nos permitiu visualizar a maneira como o sindicato intervém no cotidiano dos trabalhadores, propiciando a sensibilização ao diálogo entre os sindicalizados e seus representantes. Os dados coletados mostram a relevância do trabalho sindical na construção de uma consciência politizada nos indivíduos que compõem a categoria. A partir da perspectiva desses usuários da informação, o contato com o sindicato em muitos casos permitiu o aprimoramento de conhecimentos existentes, anterior a essa influência. Em outros casos, foi responsável por criar um veio político nos indivíduos que anteriormente nunca haviam tido contato com um movimento de cunho social ou político.

Todavia, alguns percalços recorrentes no cotidiano dos trabalhadores foram evidenciados durante nossa pesquisa como: a falta da presença dos sindicalistas nas unidades de trabalho distantes do endereço físico do sindicato, quando o sindicato não se encontra em movimento de greve em prol de melhores salários e condições de trabalho ou ainda com a falta da realização periódica das assembleias. Constatou-se ainda que, existem tensões internas e externas ao sindicato, negociações, embates políticos, que influenciam diretamente as relações sindicato e sindicalizados. No entanto, apesar dos ataques sofridos no atual cenário político do Brasil, o sindicato é reconhecido como entidade representativa, como voz ativa em prol do coletivo. 
Ainda assim, é perceptível a falta de movimentos dentro do próprio sindicato que lidem com problemas recorrentes no cotidiano dos servidores. Nesse sentido, o funcionamento efetivo dos Grupos de TrabaIho (GTs), que se encontram inativos no momento, foi apontado como uma das soluções para esses problemas.

O sindicalismo no Brasil vem passando por profundas mudanças, mas tem em voga a luta pela empregabilidade, bem como a luta por condições dignas de trabalho, devido aos problemas enfrentados por grande parte dos trabalhadores brasileiros. Portanto, cabe aos sindicatos encontrarem uma maneira de adaptar-se a nova realidade em que o capital é centro da economia mundial, lutando pela qualidade de vida e dignidade dos trabalhadores, que devem reivindicar seus direitos de forma articulada e mobilizada, independente da sua forma de trabalho (emprego formal, informal, público), uma tarefa difícil, porém necessária.

\section{REFERÊNCIAS BIBLIOGRÁFICAS}

ADÃO, Sheila Margareth Teixeira. Informação para a ação: o uso da informação como suporte às reivindicações sindicais no âmbito da segurança e da saúde do trabalhador. 2008. 190 f., enc. Dissertação (mestrado em Ciência da informação) - Universidade Federal de Minas Gerais, Escola de Ciência da Informação.

ANTUNES, Ricardo L. C. O que é sindicalismo. São Paulo: Brasiliense, 1985. 95p.

ARAÚJO, Carlos Alberto Ávila. Estudos de usuários conforme o paradigma social da ciência da informação: desafios teóricos e práticos de pesquisa. Informação \& Informação, Londrina, v. 15, n. 2, p. 23 39, jul./dez. 2010.

ARAÚJO, Eliany Alvarenga de. A construção social da informação: práticas informacionais no contexto de organizações nãogovernamentais/ONGs brasileiras. 1998. 221 f. Tese (Doutorado em 
Ciência da Informação) - Faculdade de Estudos Sociais Aplicados, Universidade de Brasília, Brasília, 1998.

. Informação, sociedade e cidadania: práticas informacionais de Organizações Não-Governamentais (ONGs) brasileiras. Informação \& Informação, Londrina, v.6, n.1, p. 31-54, jan./jun. 2001. Disponível em: <http://www.uel.br/revistas/uel/index.php/informacao/ issue/view/245> Acesso em: 02 fev.2016.

BAPTISTA, Dulce Maria. A busca da informação por parte de entidades representativas. Ciência da Informação, Brasília, v. 30, n.2, p16-19, maio/ago. 2001.

BAPTISTA, Sofia Galvão; CUNHA, Murilo Bastos. Estudo de usuários: uma visão global dos métodos de coleta de dados. Perspectivas em Ciência da Informação. v.12, n.2, p.168-184, maio/ago. 2007.

BRAGA, Kátia Soares. Aspectos relevantes para a seleção de metodologia adequada à pesquisa social em Ciência da Informação. In: MUELLER, Suzana Pinheiro Machado. Métodos para a pesquisa em Ciência da Informação. Brasília: Thesaurus, 2007. 190 p. (Ciência da informação e da comunicação).

BOITO JR., Armando. Reforma e persistência da estrutura sindical. In: BOITO JR., Armando (Org.) et al. O sindicalismo brasileiro nos anos 80. São Paulo: Paz e Terra, 1991. p. 45-91.

CHOO, C. W. Como ficamos sabendo - um modelo de uso da informação. In: , A organização do conhecimento: como as organizações usam a informação para criar significado, construir conhecimento e tomar decisões. São Paulo: Editora Senac, 2003. cap. 2, p. 63-120.

FARIA, Marcio Almeida de. O modelo sindical brasileiro. 2003. Disponível em: <http://jus.com.br/revista/texto/6665/o-modelo-sindicalbrasileiro>. Acesso em 03 de jun de 2016. 
FIGUEIREDO, Nice Menezes de. Estudos de usuários. In:

Estudos de uso e usuários da informação . Brasília: IBICT, 1994. cap. 1. p. 7-19 e cap 5. p. 65-85.

GANDRA, Tatiane Krempser; SIRIHAL DUARTE, Adriana Bogliolo. Estudos de usuários na perspectiva fenomenológica. Inf. \& Soc.: Est., João Pessoa, v.22, n.3, p. 13-23, set./dez. 2012.

. Interlocuções entre a análise de domínio e os estudos de usuários da informação: contribuições para uma abordagem sociocognitiva. In: XIV ENANCIB - Encontro Nacional de Pesquisa em Ciência da Informação, 2013. Comunicação oral apresentada ao GT03 - Mediação, Circulação e Apropriação Informação.

GUESSER, A. H. EmTese - Revista Eletrônica dos Pós-Graduandos em Sociologia Política da UFSC vol. 1, nº 1 (1), p. 149-168. 2003.

MARX, Karl . O capital. Processo de Trabalho e Processo de Produção de Mais Valia, Secção 2, O Processo de Produção de Mais Valia. Volume I, Parte III. 1944. Disponível em: <http://www.marxists.org/ portugues/marx/1867/ocapitalv1/vol1cap07.htm>. Acesso em: 10 de abr de 2016.

MATOS, Larissa. O papel dos sindicatos diante da importância do diálogo social frente aos impactos no mundo do trabalho. 2012. Disponível em : <http://www.egov.ufsc.br>. Acesso em 02 de mar de 2016.

MENEZES, Wellington Fontes. Os rumos do mercado de trabalho latinoamericano: precarização, informalidade e desertificação do emprego. In: SIMPÓSIO LUTAS SOCIAIS NA AMÉRICA LATINA: Trabalhadore(a)s em movimento: constituição de um novo proletariado?. 3., 2008. Londrina. Anais... Londrina: GEPAL-Grupo de estudos de política da América Latina, 2008. 15p.

MOLLO, Maria de Lourdes Rollemberg A Concepção Marxista de Estado: Considerações sobre Antigos debates com Novas Perspectivas. Economia, 2001, vol. 2, o número 2, páginas 347-389. 
OLIVEIRA, Dalgiza Andrade. Práticas informacionais dos dirigentes do Sindicato dos Bancários de BH e região. 2005. 137 f., enc.: Dissertação (mestrado) - Universidade Federal de Minas Gerais, Escola de Ciência da Informação.

PINTO, Flávia Virginia Melo; ARAÚJO, Carlos Alberto Ávila. Contribuição ao campo de usuários da informação: em busca dos paradoxos das práticas informacionais. Transinformação: Campinas, v 24, n 3, p 219-226, set/dez. 2012.

PINTO, Flávia Virginia Melo. Práticas informacionais na organização político-sindical dos professores da rede municipal de Belo Horizonte. 2012.152f. (Mestrado em Ciência da Informação) - Escola de Ciência da Informação, Universidade Federal de Minas Gerais, Belo Horizonte, 2012.

PINTO, Meyke Vilas Boas. Práticas informacionais para a construção da cidadania: um estudo de caso sobre os atores sindicais da Rede Municipal de Ensino de Belo Horizonte. 2004. 155 f. (Mestrado em Ciência da Informação) - Escola de Ciência da Informação, Universidade Federal de Minas Gerais, Belo Horizonte, 2004.

POCHMANN, Marcio. Desafios atuais do sindicalismo brasileiro. In: Sindicatos y nuevos movimientos sociales en América Latina. Colección Grupos de Trabajo de Clacso: Bueno Aires -Arg, 2005. Disponível em <http://migre.me/2TxnS.> Acesso em 12/03/2016.

REIS, Alcenir Soares; SILVA, Alberth Sant'Ana; MASSENSINI , Rogério Luís. Informação e cidadania: conceitos e saberes necessários à ação. In: MOURA, Maria Aparecida (Org.). Cultura informacional e liderança comunitária: concepções e práticas. Belo Horizonte, MG: PROEX/UFMG, 2011. P 17-24.

RIBEIRO, Elisa Antônia. A etnometodologia como programa de investigação educacional. Evidencia- olhares e pesquisas em saberes educacionais - Uniaraxa / ISE - ano II - nº 02- 2006- p. 187-206.

SILVA, Ronaldo Alves da. As práticas informacionais das profissionais do sexo da zona boêmia de Belo Horizonte. 2008. 
171 f. Dissertação (Mestrado em Ciência da Informação) - Universidade Federal de Minas Gerais, Escola de Ciência da Informação.

VAZQUEZ, A. S. Filosofia da Práxis. 2. ed. Rio de Janeiro: Editora Paz e Terra, 1977.

VENTURINI, Walter. A nova cara do sindicalismo brasileiro. Teoria e Debate, São Paulo, publicado dia 20/04/2006. Disponível em: <http://www.fpabramo.org.br/o-quefazemos/editora/teoria-e-debate/ edicoes-anteriores/nacional-nova-cara-dosindicalismo-brasilei>. Acesso em 21/03/2016.

Recebido em 02/10/2019

Aprovado em 24/01/2020 